\title{
Consumo e digestibilidades dos nutrientes em bovinos recebendo dietas contendo silagens de milho e sorgo, com e sem inoculante microbiano ${ }^{1}$
}

\author{
Almir Vieira Silva ${ }^{2}$, Odilon Gomes Pereira ${ }^{3}$, Sebastião de Campos Valadares Filho ${ }^{3}$, Rasmo \\ Garcia $^{3}$, Paulo Roberto Cecon ${ }^{4}$, Célia Lucia de Luces Fortes Ferreira ${ }^{5}$ \\ 1 Parte da tese de Doutorado em Zootecnia apresentada à UFV pelo primeiro autor, parcialmente financiada pela FAPEMIG. \\ 2 Instituto de Produção e Saúde Animal da Universidade Federal Rural da Amazônia - UFRA, Cx. Postal 917, CEP: 66077-530, Belém-PA. \\ ${ }^{3}$ Departamento de Zootecnia da Universidade Federal de Viçosa - UFV, CEP: 36571-000, Viçosa, MG. Bolsista do CNPq. \\ ${ }^{4}$ Departamento de Informática da UFV, CEP: 36571-000 Viçosa, MG. Bolsista do CNPq. \\ 5 Departamento de Tecnologia de Alimentos - UFV, CEP: 36571 Viçosa, MG. Bolsista do CNPq.
}

RESUMO - Avaliaram-se o consumo, as digestibilidades total, ruminal e intestinal dos nutrientes, a taxa de passagem da digesta ruminal e as concentrações de amônia e pH ruminal de dietas contendo silagens de milho e sorgo, com e sem inoculante microbiano. Utilizaram-se quatro animais Holandês x Zebu fistulados no rúmen e no abomaso, distribuídos em um quadrado latino 4 x 4 (duas silagens x dois inoculantes). Adotou-se uma relação volumoso:concentrado de 63:37\%, na MS. O consumo e as digestibilidades total e ruminal dos nutrientes não foram influenciados pelas dietas experimentais. Para os consumos de MS, PB e NDT, registraram-se, respectivamente, valores médios de 6,61; 0,75 e 3,96 kg/dia. Obtiveram-se valores médios de 61,17 e 61,$91 ; 61,43$ e 13,21 e 52,13 e 92,96\% para as digestibilidades total e ruminal da MS, PB e FDN, respectivamente. Quanto à digestibilidade intestinal dos nutrientes, detectou-se efeito do tipo de silagem apenas na FDN, observando-se maior valor para a dieta à base de silagem de milho $(9,08)$ em relação à de sorgo $(4,77 \%)$. Não houve efeito de dietas, nem do tempo de coleta, sobre os valores de $\mathrm{pH}$ ruminal, que apresentou valor médio de 5,58. Todavia, houve efeito do tempo de coleta sobre a concentração de amônia ruminal $\left(\mathrm{N}-\mathrm{NH}_{3}\right)$, estimando-se valores máximos de 10,82; 9,04; 9,47 e 8,84 mg/100 mL nas dietas com as silagens de milho não tratada e tratada com inoculante microbiano e com as silagens de sorgo não tratada e tratada com inoculante microbiano, respectivamente. As taxas de passagem médias estimadas nas dietas com silagens de milho sem e com inoculante microbiano e com silagens de sorgo sem e com inoculante microbiano, foram de 5,05; 4,29; 5,12 e 4,44\%/h, respectivamente.

Palavras-chave: amônia ruminal, fibra em detergente neutro, nutrientes digestíveis totais, pH, proteína bruta, taxa de passagem

\section{Intake, ruminal metabolism, and digestibility of nutrients in steers fed diets containing corn or sorghum silages with and without microbial inoculant}

\footnotetext{
ABSTRACT - Four crossbred Holstein x Zebu steers fitted with ruminal and abomasal cannulas were randomly assigned to a 4 x 4 Latin square to evaluate the effects of feeding corn or sorghum silages with and without microbial inoculant on intake, ruminal metabolism, total and partial digestibility of nutrients, and digesta passage rate. Diets contained, dry matter (DM) basis, a forage to concentrate ratio of 63:37. No significant differences were observed on the intakes of DM, crude protein $(\mathrm{CP})$, and total digestible nutrients, which averaged $6.61,0.75$ and $3.96 \mathrm{~kg} / \mathrm{day}$ across diets, respectively. Total and ruminal apparent digestibilities of DM, CP and neutral detergente fiber (NDF) also were not affected by diets averaging 61.17 and 61.91, 61.43 and 13.21 , and 52.13 and $92.96 \%$, respectively. However, a dietary effect was observed for the intestinaldigestibility of NDF; steers fed corn silage had greater intestinal digestibility of NDF (9.08\%) than those fed sorghum silage (4.77\%). Ruminal $\mathrm{pH}$ was not affected by diet and time of collection, with an overall mean of 5.58. Conversely, concentration of ruminal ammonia was affected by time of collection with estimated maximum values of 9.04, 10.82, 8.84, and $9.47 \mathrm{mg} / 100 \mathrm{~mL}$ for diets containing corn and sorghum silages with and without microbial inoculant, respectively. Estimated digesta passage rates of diets containing corn and sorghum silages with and without microbial inoculant were of 4.29, 5.05, 4.44, and 5.12\%/h, respectively.
}

Key Words: crude protein, neutral detergent fiber, passage rate, $\mathrm{pH}$, ruminal ammonia, total digestible nutrients 


\section{Introdução}

O consumo voluntário dos alimentos pode ser entendido, segundo Allen (1996), como a quantidade de alimento ingerido (ad libitum) por um animal ou por um grupo de animais durante um período de 24 horas, sendo sua determinação importante na avaliação da qualidade da forragem. Geralmente, mais de $50 \%$ da variação é atribuída aos nutrientes digestíveis. É necessário maior entendimento da natureza da ação dos aditivos comumente utilizados na nutrição de ruminantes visando aumentar o fluxo da digesta pelo retículo-rúmen e que atuam sobre a digestão e passagem do alimento pelo trato digestivo, como ocorre para o mecanismo de feedback. Nestes estudos, torna-se fundamental a determinação do consumo voluntário, essencial para avaliação da qualidade da forragem e mensuração de seu potencial sobre o desempenho de ruminantes.

A digestão pode ser definida, em termos gerais, como a soma dos processos pelos quais macromoléculas dos alimentos são degradadas em compostos menores, passíveis de absorção ao longo do trato gastrointestinal (Merchen, 1988).

Há uma importante variação na associação dos componentes químicos ao consumo e à digestibilidade. A lignina e a FDA são mais intimamente associadas à digestibilidade, enquanto a FDN está mais relacionada ao consumo voluntário (Van Soest et al., 1978). Segundo Hvelplund (1991) e Rodrigues (1998), os carboidratos contribuem com 70 a $80 \%$ da MS das rações (o restante é composto de proteínas, gorduras e minerais). Por isso, Mertens (1996) destaca os carboidratos como os principais fornecedores de energia para bovinos, embora constituam a fração mais limitante ao consumo animal e à digestibilidade dos nutrientes nos volumosos.

Segundo Meeske \& Bolsen (1998), com o avanço na maturidade da planta, ocorre redução da digestibilidade de alguns nutrientes, sobretudo daqueles relacionados à parede celular. Esses autores demonstraram que silagens com alta proporção de grãos podem apresentar diluições dos efeitos dos componentes da fibra, como resultado da formação do amido no grão com o avançar da idade da planta. Em forragens conservadas, o período de armazenamento também influencia a concentração de fibra e sua digestibilidade. Sanderson (1993), comparando silagens de milho e sorgo armazenadas por 30 e 160 dias, observou aumento da concentração de FDN e FDA com o passar do tempo. No entanto, verificou aumento dos valores da digestibilidade das silagens que permaneceram mais tempo ensiladas, o que comprova a existência de possíveis mecanismos químicos, físicos e biológicos envolvidos nas mudanças da digestibilidade da fração fibrosa.

De acordo com Huhtanen (1993), os efeitos da composição de alimentos concentrados sobre o consumo de silagens têm revelado que a maior rapidez da fermentação do amido em relação aos constituintes da parede celular é a principal causa da redução do $\mathrm{pH}$ ruminal, diminuindo a atividade celulolítica. Esse autor relatou que a moderada participação de alimentos concentrados (abaixo de 50\%) tem pequeno efeito sobre o $\mathrm{pH}$ do rúmen e, conseqüentemente, apresenta pouco impacto sobre a taxa de degradação da MS de silagens. Portanto, uma das formas de se conseguir máximo consumo de energia é a manipulação correta da relação volumoso:concentrado na ração, que, segundo Pereira \& Ribeiro (2001), permite corrigir deficiências de nutrientes, seja pela mais baixa qualidade da forragem, seja pela impossibilidade de atendimento dos requerimentos de categorias de animais com alto potencial de desempenho. Portanto, por meio do balanceamento de rações, é possível maximizar os aspectos benéficos da fermentação no rúmen e minimizar as perdas decorrentes da fermentação (Russel et al., 1992).

Dietas contendo silagens tratadas com inoculantes microbianos têm promovido pequenos aumentos no consumo de MS e na digestibilidade de nutrientes, resultando em melhor utilização da energia da dieta (Kung Jr., 2001) e podendo, inclusive, melhorar o desempenho animal (Muck, 1993). No entanto, a causa desse efeito ainda não pôde ser devidamente elucidada (Kung Jr., 1996).

Vários autores tentam elucidar como as silagens tratadas com inoculantes microbianos podem direta ou indiretamente resultar em maior aceitabilidade, consumo e digestibilidade. Acredita-se que os resultados positivos decorram de efeitos probióticos contidos nestes produtos ou de outros efeitos não-mensuráveis (Kung Jr. \& Muck, 1997), no entanto, sabe-se, na atualidade, que estes efeitos são decorrentes de cepas específicas de microrganismos e não foram identificados de modo conclusivo se as silagens inoculadas com microrganismos podem trazer benefícios diretos para os ruminantes (Weiberg et al., 2004). Segundo Weiberg \& Muck (1996), o efeito probiótico inibe microrganismos prejudiciais à fermentação dentro do silo e ainda promove benefícios à flora ruminal e intestinal de ruminantes, favorecendo o maior aproveitamento dos nutrientes da dieta. No entanto, Dewhurst et al. (2000) destacaram que não existe efeito comprovado relacionando o uso de aditivos em silagens a vantagens adicionais à produção microbiana ruminal. Entretanto, acredita-se que, em algumas situações específicas, possa ocorrer a quebra de açúcares residuais 
e de proteína como importante fonte de nutrientes para os microrganismos do rúmen.

Objetivou-se com este trabalho avaliar o consumo, as digestibilidades total e parcial de nutrientes, o $\mathrm{pH}$, concentração de amônia ruminal e a taxa de passagem em bovinos fistulados no rúmen e no abomaso recebendo dietas contendo silagens de milho e de sorgo, confeccionadas com e sem inoculante microbiano.

\section{Material e Métodos}

O experimento foi conduzido na Central de Experimentação, Pesquisa e Extensão do Triângulo Mineiro - CEPET, em Capinópolis - MG, no período de março a agosto de 2000. O milho (AG 1051) e o sorgo (AG 2002) foram cultivados em área destinada à produção de silagem para atendimento das necessidades da CEPET, respeitando-se as recomendações de plantio do produtor de sementes. A colheita das respectivas forrageiras ocorreu aos 118 e 110 dias após o plantio, quando os grãos se encontravam no estádio farináceoduro, com auxílio de uma colhedeira de forragem JF, modelo JF90, ajustada para tamanho médio de partículas igual a $2 \mathrm{~cm}$. Foram confeccionados quatro silos de superfície (dois para cada espécie forrageira) com capacidade para aproximadamente 50 toneladas. Utilizando-se um pulverizador costal (20 L), aplicou-se o inoculante MAIZE-ALL (Alltech do Brasil), contendo Enterococcus faecium (10 bilhões de ufc/g), Lactobacillus plantarum (10 bilhões de ufc/g), Pediococcus acidilactici (1 bilhão de ufc/g) e enzimas amilolíticas (1,5\%), celulolíticas (1,5\%) e proteolíticas $(2,0 \%)$, efetuando-se a pulverização sobre o material picado, conforme recomendação do fabricante. Adicionou-se água pura à forragem não tratada, em quantidade equivalente à aplicada na forragem tratada. $\mathrm{O}$ material permaneceuacondicionado por 120 dias.

Foram utilizados quatro novilhos Holandês x Zebu (castrados, com $299 \mathrm{~kg}$ de PV inicial), fistulados no rúmen e no abomaso, distribuídos em quadrado latino 4 x 4 (duas silagens $\mathrm{x}$ dois inoculantes). Os animais foram mantidos em baias individuais parcialmente cobertas $\left(8 \mathrm{~m}^{2}\right)$, com comedouros de madeira e bebedouros cilíndricos de alvenaria.

As dietas foram formuladas segundo o NRC (1996), objetivando-se ganho de peso de $1,2 \mathrm{~kg} / \mathrm{dia}$, adotando-se relação volumoso:concentrado de 63:37\%, na MS. Foram calculados dois concentrados: concentrado 1 (C1), para atender aos requerimentos dos animais que receberam dietas à base da silagem de sorgo, e concentrado 2 (C2), fornecido aos animais que receberam dietas à base de silagem de milho.
Para análise da composição bromatológica das dietas, amostras das silagens e dos concentrados foram pré-secas em estufa de ventilação forçada $\left(60-65^{\circ} \mathrm{C}\right.$, por 72 horas $)$ e, posteriormente, trituradas em moinho tipo Willey, com peneira de $1 \mathrm{~mm}$, sendo acondicionadas em frascos de vidro com tampa para a realização das análises laboratoriais. Nas amostras, determinaram-se os teores de MS em estufa a $105^{\circ} \mathrm{C}$ e os teores de MO, PB, EE, CT, CNF, FDN, FDA, HEM, CEL e LIG, conforme descrito por Silva (1998). O pH foi determinado utilizando-se um potenciômetro, após a extração do suco das silagens com prensa hidráulica.

Como pode ser observado na Tabela 1 , houve pequenas diferenças dentro de silagens, atribuídas à eminente variabilidade de resultados, peculiar das metodologias laboratoriais empregadas. A composição percentual dos concentrados utilizados nas quatro dietas encontra-se descrita na Tabela 2 e a dos principais constituintes das dietas experimentais, na Tabela 3 .

A alimentação foi fornecida duas vezes ao dia, às $7 \mathrm{~h} 15$ e 13h15, excetuando-se o dia de coleta de amostras para determinação do pH e da concentração de amônia ruminal, quando toda a dieta foi fornecida pela manhã. A quantidade de alimentos fornecida diariamente foi calculada permitindo-se aproximadamente $10 \%$ de sobras.

Cada período experimental teve duração de 18 dias, sendo nove para adaptação dos animais às dietas e nove para coletas, dos quais seis foram destinados à coleta de digesta de abomaso e fezes, para determinação das digestibilidades total e parcial, um para determinação do $\mathrm{pH}$ e da amônia ruminal e dois para coleta de digesta ruminal, para determinação da taxa de passagem (Kp).

As coletas de digesta do abomaso e de fezes foram realizadas diariamente, durante seis dias, em intervalos de 26 horas, iniciando-se às $7 \mathrm{~h}$ do 10 dia e terminando às $17 \mathrm{~h}$ do $6 \underline{0}$ dia, sendo armazenadas em freezer.

As coletas de fluido ruminal para determinação do $\mathrm{pH}$ e dos teores de amônia ruminal foram realizadas antes da alimentação e 2, 4, 6 e 8 horas após a alimentação. Coletaram-se, via fístula ruminal, aproximadamente $200 \mathrm{~mL}$ de líquido ruminal para medição do $\mathrm{pH}$, imediatamente após a coleta, com peagâmetro digital. Em seguida, adicionaram-se $2 \mathrm{~mL}$ de $\mathrm{H}_{2} \mathrm{SO}_{4}, 25 \%$ a cada amostra, que foi armazenada em freezer, para posteriores análises de $\mathrm{N}-\mathrm{NH}_{3}$.

Para estimativa das taxas de passagem, foram infundidos $20 \mathrm{~g}$ de óxido de cromo, em dose única, via fístula ruminal, efetuando-se as coletas de conteúdo ruminal antes e 2, 4, 6, 9, 12, 24, 36 e 48 horas da infusão. As amostras foram imediatamente secas a $60-65^{\circ} \mathrm{C}$ por 72 horas em estufa com ventilação forçada e, posteriormente, foram processadas 
Tabela 1 - Teores médios de nutrientes e valores de $\mathrm{pH}$ obtidos nas silagens de milho e sorgo, com e sem inoculante microbiano, e nos respectivos concentrados

Table 1 - Chemical composition and $\mathrm{pH}$ values of corn or sorghum silages with and without microbial inoculant

\begin{tabular}{|c|c|c|c|c|c|c|}
\hline \multirow{3}{*}{ Item } & \multicolumn{6}{|c|}{$\begin{array}{l}\text { Silagem } \\
\text { Silage }\end{array}$} \\
\hline & \multicolumn{2}{|c|}{$\begin{array}{l}\text { Milho } \\
\text { Corn }\end{array}$} & \multicolumn{2}{|c|}{$\begin{array}{c}\text { Sorgo } \\
\text { Sorghum }\end{array}$} & \multicolumn{2}{|c|}{$\begin{array}{c}\text { Concentrado } \\
\text { Concentrate }\end{array}$} \\
\hline & $\begin{array}{l}\text { Sem inoculante } \\
\text { Without inoculant }\end{array}$ & $\begin{array}{l}\text { Com inoculante } \\
\text { With inoculant }\end{array}$ & $\begin{array}{l}\text { Sem inoculante } \\
\text { Without inoculant }\end{array}$ & $\begin{array}{l}\text { Com inoculante } \\
\text { With inoculant }\end{array}$ & 1 & 2 \\
\hline $\operatorname{MS}(D M)(\%)^{1}$ & 30,74 & 30,55 & 27,29 & 26,60 & 91,18 & 91,24 \\
\hline $\mathrm{MO}(O M)^{1}$ & 91,49 & 91,42 & 91,23 & 91,47 & 88,82 & 89,45 \\
\hline $\mathrm{PB}(C P)^{1}$ & 7,22 & 7,00 & 5,58 & 5,48 & 20,02 & 20,12 \\
\hline $\mathrm{EE}^{1}$ & 2,13 & 1,86 & 1,87 & 2,41 & 9,87 & 9,26 \\
\hline $\mathrm{CT}(T C)^{1}$ & 82,14 & 82,56 & 83,78 & 83,58 & 58,93 & 60,07 \\
\hline $\operatorname{FDN}(N D F)^{1}$ & 50,59 & 53,06 & 62,38 & 59,79 & 23,35 & 19,89 \\
\hline $\mathrm{CNF}(N F C)^{1}$ & 31,55 & 29,50 & 21,40 & 23,79 & 35,58 & 40,18 \\
\hline FDA $(A D F)^{1}$ & 26,32 & 27,55 & 35,65 & 35,09 & 4,82 & 4,27 \\
\hline HEM $^{1}$ & 22,90 & 23,57 & 25,08 & 22,75 & 3,64 & 3,24 \\
\hline $\mathrm{CEL}^{1}$ & 22,17 & 23,10 & 28,77 & 27,75 & 16,92 & 14,31 \\
\hline $\mathrm{LIG}^{1}$ & 2,81 & 2,53 & 4,98 & 4,96 & 0,84 & 0,73 \\
\hline $\mathrm{pH}^{2}$ & 3,69 & 3,87 & 3,77 & 3,81 & & \\
\hline
\end{tabular}

$1 \%$ da MS (\% DM).

2 Determinado segundo Bolsen et al. (1992) (Determined according to Bolsen et al., 1992).

Tabela 2 - Composição percentual dos ingredientes nos concentrados 1 e 2, com base na matéria natural

Table 2 - Ingredient composition of concentrate, expressed as fed basis

\begin{tabular}{lcr}
\hline $\begin{array}{l}\text { Concentrado } \\
\text { Concentrate }\end{array}$ & \multicolumn{2}{c}{$\begin{array}{c}\text { Ingrediente } \\
\text { Ingredient }\end{array}$} \\
\cline { 2 - 3 } & $1^{1}$ & $2^{2}$ \\
\hline Fubá de milho (Ground corn) & 61,33 & 65,72 \\
Grão de soja integral (Whole soybean) & 35,24 & 31,72 \\
Uréia (Urea) & 1,17 & 0,98 \\
Sulfato de amônia (Ammonium sulfate) & 0,13 & 0,11 \\
Suplemento mineral (Mineral mixture) & 2,12 & 2,13 \\
\hline
\end{tabular}

${ }^{1}$ Suplemento mineral (\% de ingredientes) (Mineral mixture, composition,\%): calcário (limestone) 21,5\%, fosfato bicálcico (dicalcium phosphate) 50,83\%, cloreto de sódio (sodium chloride) $27,31 \%$ e premix mineral (mineral premix) $0,36 \%$.

2 Suplemento mineral (\% de ingredientes) (Mineral mixture, composition,\%): calcário (limestone) 21,59\%, fosfato bicálcico (dicalcium phosphate) 51,06, cloreto de sódio (sodium chloride) $26,99 \%$ e premix mineral (mineral premix) $0,36 \%$.

em moinho tipo Willey com peneira de $1 \mathrm{~mm}$, sendo armazenadas em vidros para posteriores análises dos teores de MS e óxido de cromo. A taxa de passagem foi calculada utilizando-se o modelo $\hat{Y}=a \cdot e^{-k t}$, proposto por Czerkawski (1986), em que Y é a concentração do indicador no tempo "t" e "a", a concentração do indicador. A taxa de passagem também foi estimada utilizando-se as equações propostas pelo NRC (2001): $\mathrm{Kp}=3,054+0,614 \mathrm{X}_{1} \quad$ e $\mathrm{Kp}=2,904+1,375 \mathrm{X}_{1}-0,020 \mathrm{X}_{2}$, para estimativa da taxa de passagem $(\mathrm{kp})$ de forragens úmidas e alimentos concentrados, respectivamente, em que $\mathrm{X}_{1}=$ consumo de $\mathrm{MS}$ em relação ao peso vivo e $\mathrm{X}_{2}=$ porcentagem de concentrado na dieta.
Estimou-se, ainda, a produção de proteína microbiana (PM), segundo o NRC (2001), considerando-se produção de $130 \mathrm{~g}$ de PB microbiana para cada kg de NDT consumido.

O consumo das dietas foi determinado por meio da pesagem e amostragem diária dos alimentos ofertados e das sobras, para cada animal, em cada período de coletas. Para determinação da MS fecal, utilizou-se o óxido de cromo, ministrado via fístula ruminal, em dose diária de $20 \mathrm{~g}$, às $11 \mathrm{~h}$, durante os sete dias finais do período de adaptação e os seis dias do período de coletas.

Ao final de cada período experimental, efetuou-se o descongelamento das amostras de sobras, fezes, digesta de abomaso e alimentos fornecidos, efetuando-se em seguida a pré-secagem em estufa com ventilação forçada a $60-65^{\circ} \mathrm{C}$, por 72 horas. As amostras de digesta de abomaso foram pesadas, antes e após a retirada da estufa, para determinação da porcentagem de amostra seca ao ar (ASA). Depois de secas, todas as amostras foram trituradas em moinho tipo Willey com peneira de $1 \mathrm{~mm}$ e acondicionadas em vidros fechados com tampas plásticas, sendo analisadas posteriormente no Laboratório de Nutrição Animal do Departamento de Zootecnia da Universidade Federal de Viçosa. Os teores de MS, MO, PB, EE e FDN nas amostras de alimentos fornecidos, sobras, digestas de abomaso e fezes, além de cromo, nas duas últimas, foram determinados segundo metodologias descritas por Silva (1998).

Os teores de carboidratos totais (CT) foram obtidos por meio da equação citada por Sniffen et al. (1992): CT (\%MS) $=100-(\% \mathrm{~PB}+\% \mathrm{EE}+\%$ cinzas $)$. Para o cálculo do consumo de NDT, utilizou-se a equação citada por Sniffen et al. 
Tabela 3 - Teores médios de nutrientes e energia metabolizável (EM) das dietas contendo silagens de milho e sorgo, com e sem inoculante microbiano

Table 3 - Chemical composition and metabolizable energy (ME) of diets containing corn or sorghum silages with and without microbial inoculant

\begin{tabular}{|c|c|c|c|c|}
\hline \multirow{3}{*}{ Item } & \multicolumn{4}{|c|}{$\begin{array}{l}\text { Silagem } \\
\text { Silage }\end{array}$} \\
\hline & \multicolumn{2}{|c|}{$\begin{array}{c}\text { Milho } \\
\text { Corn }\end{array}$} & \multicolumn{2}{|c|}{$\begin{array}{c}\text { Sorgo } \\
\text { Sorghum }\end{array}$} \\
\hline & $\begin{array}{l}\text { Sem inoculante } \\
\text { Without inoculant }\end{array}$ & $\begin{array}{l}\text { Com inoculante } \\
\text { With inoculant }\end{array}$ & $\begin{array}{l}\text { Sem inoculante } \\
\text { Without inoculant }\end{array}$ & $\begin{array}{c}\text { Com inoculante } \\
\text { With inoculant }\end{array}$ \\
\hline $\operatorname{MS}(\%)(D M, \%)$ & 53,13 & 53,00 & 51,30 & 50,10 \\
\hline $\mathrm{MO}(O M)^{1}$ & 90,73 & 90,69 & 90,33 & 90,47 \\
\hline $\mathrm{PB}(C P)^{1}$ & 10,92 & 10,92 & 11,01 & 11,04 \\
\hline $\mathrm{EE}^{1}$ & 4,77 & 4,60 & 4,88 & 5,23 \\
\hline $\operatorname{CHOT}(T C)^{1}$ & 80,52 & 80,51 & 80,37 & 80,61 \\
\hline FDN $(N D F)^{1}$ & 39,24 & 40,79 & 47,71 & 46,02 \\
\hline $\mathrm{CNF}(N F C)^{1}$ & 35,80 & 34,38 & 26,73 & 28,18 \\
\hline $\operatorname{NDT}(T D N)^{3}$ & 65,74 & 61,48 & 62,09 & 62,80 \\
\hline $\mathrm{EM}(M E)^{2}$ & 2,59 & 2,68 & 2,47 & 2,55 \\
\hline
\end{tabular}

$1 \%$ na MS (\% of DM).

${ }^{2} \mathrm{Mcal} / \mathrm{kg} \mathrm{MS}$ (Mcal/kg of DM).

3 Estimado segundo o NRC (2001), \% na MS [estimated according to NRC (2001)].

(1992): $\mathrm{NDT}_{\mathrm{C}}=(\mathrm{PBc}-\mathrm{PBf})+2,25(\mathrm{EEc}-\mathrm{EEf})+(\mathrm{CTc}-\mathrm{CTf}), \mathrm{em}$ que $\mathrm{c}$ representa os consumos e $\mathrm{f}$, as excreções fecais dos respectivos nutrientes. Os CNF foram obtidos pela fórmula: $\mathrm{CNF}=100-(\% \mathrm{~PB}+\% \mathrm{EE}+\% \mathrm{FDN}+\%$ cinzas $)$, como proposto pelo NRC (2001). A concentração de NDT das silagens e dos concentrados foi calculada pela equação proposta pelo NRC (2001): NDT = DVCNF + DVPB + $\left(\right.$ DVAG $\left.^{*} 2,25\right)+$ DVFDN, em que: DVPB $=$ digestibilidade verdadeira da PB; DVAG = digestibilidade verdadeira dos ácidos graxos; e DVFDN = digestibilidade verdadeira da FDN. A concentração de EM, em Mcal $/ \mathrm{kg}$, foi obtida pela equação: $\mathrm{EM}=$ \%NDT x 4,409 x 0,82 (Sniffen et al., 1992).

Os dados de consumo e digestibilidades total, ruminal e intestinal foram submetidos à análise de variância e as médias foram comparadas pelo teste de Student-NewmanKeuls (SNK), a 5\% de probabilidade, utilizando-se o programa SAEG versão 8.0 (UFV, 2000).

Os dados de $\mathrm{pH}$ e concentração de amônia ruminal obtidos foram analisados em esquema de parcelas subdivididas, em que as dietas constituíram as parcelas e os tempos de amostragem as subparcelas. Os modelos foram selecionados utilizando-se como critério a significância dos coeficientes de regressão pelo teste $t$, o coeficiente de determinação e o conhecimento do fenômeno estudado.

\section{Resultados e Discussão}

O consumo médio de nutrientes, de modo geral, não foi afetado pelos fatores estudados (silagem, inoculante ou suas interações), o que evidencia a inexistência de benefícios quanto ao consumo destes nutrientes quando o inoculante microbiano foi empregado, à exceção do consumo de $\mathrm{CNF}$, que foi superior $(\mathrm{P}<0,01)$ para a dieta com silagem de milho $(1,97 \mathrm{~kg} /$ dia $)$ em relação àquela com silagem de sorgo $(1,44 \mathrm{~kg} / \mathrm{dia})$, provavelmente em virtude da possível presença de maiores quantidades de grãos nas dietas formuladas com silagens de milho (Tabela 4). Os valores médios e os respectivos coeficientes de variação referentes aos dados de consumos dos demais nutrientes encontram-se também na Tabela 4. Os consumos de MS, em kg/dia e $\% \mathrm{PV}$, apresentaram valores médios de 6,61 e 2,03, respectivamente. Luther (1986), em ensaio com bovinos recebendo dietas contendo $90 \%$ de silagem de milho (na MS), suplementados com $10 \%$ de concentrado, também não observou efeito de inoculante microbiano sobre o consumo de MS. Cleale et al. (1990), no entanto, observaram diferenças significativas no consumo de MS, em kg/dia e em \% PV, e registraram valores de 7,93 e 9,62 kg/dia e de 2,03 e $2,45 \%$ do PV, respectivamente, nos novilhos alimentados com silagens de milho sem e com inoculante microbiano. O consumo médio de MO, neste estudo, foi de $5,90 \mathrm{~kg} / \mathrm{dia}$.

Obtiveram-se valores médios de 0,$75 ; 0,33 ; 2,49 ; 4,97$ e $3,96 \mathrm{~kg} / \mathrm{dia}$, respectivamente, para os consumos de PB, EE, FDN, CT e NDT. O consumo de FDN em \%PV apresentou comportamento semelhante entre tratamentos, registrando-se valor médio de 0,76 , próximo ao de $0,86 \%$ do $\mathrm{PV}$, registrado por Cavalcante (2002) em bovinos fistulados no rúmen consumindo dieta contendo silagem de milho do mesmo híbrido utilizado neste trabalho. 
Não foram observados efeitos $(\mathrm{P}>0,05)$ de silagem, de inoculantes ou da interação silagem $\times$ inoculante sobre os coeficientes de digestibilidade total de MS, MO, PB, EE, CT, FDN e CNF, que apresentaram valores médios de 61,17; 66,$58 ; 61,43 ; 87,25 ; 68,15 ; 52,13$ e $77,47 \%$, respectivamente (Tabela 5). Resultado semelhante foi observado por Froetschel et al. (1997) na avaliação da digestibilidade da MS e FDN de dietas contendo silagens de milho e sorgo, com e sem inoculante microbiano.

Muck (1993), em revisão, observou melhora nas digestibilidades da MS e FDN, como resultado do uso de inoculantes microbianos, em 55 e $30 \%$ dos estudos avaliados, respectivamente. $\mathrm{O}$ autor atribuiu essa resposta positiva na digestibilidade da FDN a uma hidrólise ácida da hemicelulose, visto que as bactérias acidoláticas não degradam componentes da parede celular. Neste trabalho, observou-se menor valor numérico para a digestibilidade da FDN da silagem de milho tratata com inoculante microbiano, provalmente em decorrência da prévia hidrólise da hemicelulose ao longo da fase de fermentação, reduzindo o quantitativo de substratos a serem digeridos. No entanto, são necessárias investigações mais precisas para elucidar esta especulação. Muck (1993) destacou ainda que os benefícios sobre o desempenho animal foram estreitamente relacionados aos da digestibilidade, pois, de 31 experimentos em que se avaliaram ambas as variáveis, o desempenho animal foi melhorado em nove dos 16 experimentos nos quais os inoculantes microbianos melhoraram a digestibilidade da MS. Quando a digestibilidade não foi afetada pelos inoculantes, somente em dois, de um total de 15 experimentos, obteve-se resposta positiva sobre o desempenho animal. Segundo o autor, o aumento na digestibilidade pode ser a chave para a explicação da melhora no desempenho animal em dietas com silagens tratadas com inoculantes microbianos.

A exemplo do observado na digestibilidade total, não se detectou efeito de silagem, inoculante ou de sua interação nos coeficientes de digestibilidade ruminal de MS, MO, PB, EE, CT, FDN e CNF, que apresentaram valores médios de 61,91; 63,92; 13,$21 ;-2,81 ; 79,39,92,96$ e $83,43 \%$, respectivamente.

$\mathrm{O}$ valor médio de digestibilidade aparente total da MS da dieta contendo silagem de milho tratada com inoculante foi superior ao observado para digestibilidade aparente ruminal da MS, resultado atribuído ao erro experimental, que contribuiu para a redução do nível de NDT da dieta. Ressalta-se que, em virtude do elevado valor de coeficiente de variação, as diferenças observadas nas médias não foram estatisticamente significativas $(\mathrm{P}>0,05)$. O coeficiente de digestibilidade ruminal negativo do EE foi ocasionado pela síntese de lipídios microbianos no rúmen, que faz com que a quantidade de lipídios que chegam ao abomaso seja superior à quantidade ingerida (Ladeira et al., 1999; Dias et al., 2000; Ribeiro et al., 2001).

Tabela 4 - Consumos médios diários de nutrientes das dietas contendo silagens de milho e de sorgo, formuladas com e sem inoculante microbiano

Table 4 - Daily intake of nutrients of diets containing corn or sorghum silages with and without microbial inoculant

\begin{tabular}{|c|c|c|c|c|c|c|}
\hline \multirow{4}{*}{ Item } & \multicolumn{4}{|c|}{$\begin{array}{l}\text { Silagem } \\
\text { Silage }\end{array}$} & \multirow{4}{*}{$\begin{array}{l}\text { Média } \\
\text { Mean }\end{array}$} & \multirow{4}{*}{$\mathrm{CV}(\%)$} \\
\hline & \multirow{2}{*}{\multicolumn{2}{|c|}{$\begin{array}{l}\text { Milho } \\
\text { Corn }\end{array}$}} & \multirow{2}{*}{\multicolumn{2}{|c|}{$\begin{array}{c}\text { Sorgo } \\
\text { Sorghum }\end{array}$}} & & \\
\hline & & & & & & \\
\hline & $\begin{array}{l}\text { Sem inoculante } \\
\text { Without inoculant }\end{array}$ & $\begin{array}{l}\text { Com inoculante } \\
\text { With inoculant }\end{array}$ & $\begin{array}{l}\text { Sem inoculante } \\
\text { Without inoculant }\end{array}$ & $\begin{array}{l}\text { Com inoculante } \\
\text { With inoculant }\end{array}$ & & \\
\hline \multicolumn{7}{|c|}{$\begin{array}{c}\text { Consumo (kg/dia) } \\
\text { Intake (kg/day) }\end{array}$} \\
\hline $\operatorname{MS}(D M)$ & 6,63 & 6,63 & 6,53 & 6,63 & 6,61 & 9,11 \\
\hline $\mathrm{MO}(O M)$ & 6,10 & 5,87 & 5,73 & 5,88 & 5,90 & 8,40 \\
\hline $\mathrm{PB}(C P)$ & 0,80 & 0,77 & 0,72 & 0,71 & 0,75 & 8,10 \\
\hline $\mathrm{EE}$ & 0,33 & 0,31 & 0,33 & 0,35 & 0,33 & 10,01 \\
\hline $\mathrm{CT}(T C)$ & 5,15 & 5,03 & 4,89 & 4,80 & 4,97 & 8,63 \\
\hline FDN $(N D F)$ & 2,46 & 2,40 & 2,60 & 2,48 & 2,49 & 9,69 \\
\hline $\mathrm{CNF}(N F C)$ & $2,05 \mathrm{a}$ & $1,88 \mathrm{a}$ & $1,47 \mathrm{~b}$ & $1,41 \mathrm{~b}$ & & 14,44 \\
\hline \multirow[t]{2}{*}{$\operatorname{NDT}(T D N)$} & 4,23 & 4,00 & 3,78 & 3,81 & 3,96 & 11,76 \\
\hline & \multicolumn{4}{|c|}{$\begin{array}{c}\text { Consumo }(\% \mathrm{PV}) \\
\text { Intake }(\% B W)\end{array}$} & & \\
\hline $\mathrm{MS}(D M)$ & 1,98 & 2,04 & 1,99 & 2,10 & 2,03 & 10,17 \\
\hline $\operatorname{FDN}(N D F)$ & 0,73 & 0,73 & 0,79 & 0,78 & 0,76 & 10,36 \\
\hline
\end{tabular}

Médias seguidas por letras diferentes na linha diferem a $5 \%$ de probabilidade pelo teste SNK. 
A alta digestibilidade ruminal da FDN (103,5\%) quando utilizada a dieta constituída de silagem de sorgo com inoculante microbiano foi ocasionada, provavelmente, por problemas metodológicos, pois, segundo Mertens (1996), carboidratos fibrosos não são digeridos de forma completa.

Os coeficientes de digestibilidade ruminal da MS, MO e PB das silagens utilizadas neste estudo foram semelhantes aos observados por Caldas Neto et al. (1999), ao avaliarem a digestibilidade ruminal de silagem de milho e de diferentes rações concentradas com relações volumoso:concentrado de 45:55 e 40:60\%.

Também na Tabela 5 encontram-se os coeficientes médios da digestibilidade intestinal dos nutrientes. Detectou-se efeito de silagem no nível de $1 \%$ de probabilidade (teste de Fisher) para a digestibilidade intestinal da FDN, que foi maior na dieta contendo silagem de milho $(9,08 \%) \mathrm{em}$ relação àquela à base de silagem de sorgo (4,77\%). O fluxo negativo de FDN neste compartimento pode ter refletido o comportamento observado (efeito de silagem). Os coeficientes de digestibilidade intestinal da MS deste estudo foram semelhantes aos observados por Caldas Neto et al. (1999), enquanto os coeficientes da MO e PB mostraram-se inferiores e superiores, respectivamente. Não houve efeito de dietas, inoculante e da interação dietas $\times$ inoculante sobre o coeficiente de digestitilidade intestinal de CNF, que apresentou valor médio de $16,25 \%$.

Não houve efeito de dietas, nem dos tempos de coleta, sobre os valores de $\mathrm{pH}$ ruminal, cujos valores médios variaram de 5,58 a 6,14 nas dietas contendo, respectivamente, silagens de milho e sorgo sem inoculantes (Tabela 6). Esses valores encontram-se acima da faixa de 5,0-5,5, abaixo da qual a digestão da fibra pode ser inibida (Hoover, 1986).

Também não houve efeito das dietas sobre as concentrações ruminais de $\mathrm{N}-\mathrm{NH}_{3}$. No entanto, detectou-se efeito

Tabela 5 - Digestibilidades total, ruminal e intestinal de nutrientes de dietas contendo silagens de milho e sorgo, com e sem inoculante microbiano

Table 5 - Total, ruminal and intestinal apparent digestibilities of nutrientes of diets containing corn or sorghum silages with and without microbial inoculant

\begin{tabular}{|c|c|c|c|c|c|c|}
\hline \multirow{3}{*}{ Item } & \multicolumn{4}{|c|}{$\begin{array}{l}\text { Silagem } \\
\text { Silage }\end{array}$} & \multirow{3}{*}{$\begin{array}{l}\text { Média } \\
\text { Mean }\end{array}$} & \multirow{3}{*}{$\mathrm{CV}(\%)$} \\
\hline & \multicolumn{2}{|c|}{$\begin{array}{l}\text { Milho } \\
\text { Corn }\end{array}$} & \multicolumn{2}{|c|}{$\begin{array}{c}\text { Sorgo } \\
\text { Sorghum }\end{array}$} & & \\
\hline & $\begin{array}{l}\text { Sem inoculante } \\
\text { Without inoculant }\end{array}$ & $\begin{array}{l}\text { Com inoculante } \\
\text { With inoculant }\end{array}$ & $\begin{array}{l}\text { Sem inoculante } \\
\text { Without inoculant }\end{array}$ & $\begin{array}{l}\text { Com inoculante } \\
\text { With inoculant }\end{array}$ & & \\
\hline \multicolumn{7}{|c|}{$\begin{array}{c}\text { Digestibilidade total }(\%) \\
\text { Total tract digestibilty }\end{array}$} \\
\hline $\operatorname{MS}(D M)$ & 63,67 & 59,83 & 60,10 & 61,07 & 61,17 & 8,49 \\
\hline $\mathrm{MO}(O M)$ & 68,45 & 66,81 & 64,68 & 66,38 & 66,58 & 7,93 \\
\hline $\mathrm{PB}(C P)$ & 65,33 & 60,01 & 60,21 & 60,17 & 61,43 & 14,52 \\
\hline $\mathrm{EE}$ & 85,96 & 89,46 & 87,37 & 86,21 & 87,25 & 4,77 \\
\hline $\mathrm{CT}(T C)$ & 69,95 & 68,48 & 65,94 & 68,21 & 68,15 & 6,99 \\
\hline $\mathrm{FDN}(N D F)$ & 56,92 & 48,85 & 50,43 & 52,30 & 52,13 & 19,44 \\
\hline $\mathrm{CNF}(N F C)$ & 75,54 & 74,87 & 81,59 & 77,88 & 77,47 & 8,28 \\
\hline \multicolumn{7}{|c|}{$\begin{array}{c}\text { Digestibilidade ruminal (\% da digestibilidade total) } \\
\text { Ruminal digestibilty (\% of total digestibility) }\end{array}$} \\
\hline $\operatorname{MS}(D M)$ & 64,17 & 62,13 & 62,15 & 59,20 & 61,91 & 6,44 \\
\hline $\mathrm{MO}(O M)$ & 65,12 & 64,97 & 62,48 & 63,11 & 63,92 & 9,67 \\
\hline $\mathrm{PB}(C P)$ & 13,69 & 19,59 & 9,81 & 9,74 & 13,21 & 83,33 \\
\hline $\mathrm{EE}$ & $-3,84$ & $-2,24$ & $-2,57$ & $-2,57$ & $-2,81$ & $-524,27$ \\
\hline $\mathrm{CT}(T C)$ & 81,82 & 76,36 & 82,27 & 77,11 & 79,39 & 6,40 \\
\hline $\mathrm{FDN}(N D F)$ & 91,36 & 91,50 & 85,48 & 103,50 & 92,96 & 9,60 \\
\hline $\mathrm{CNF}(N F C)$ & 83,72 & 82,14 & 82,81 & 85,04 & 83,43 & 2,43 \\
\hline \multicolumn{7}{|c|}{$\begin{array}{c}\text { Digestibilidade intestinal }(\%) \\
\text { Intestinal digestibility }\end{array}$} \\
\hline $\operatorname{MS}(D M)$ & 35,83 & 36,80 & 37,85 & 40,80 & 37,82 & 8,51 \\
\hline $\mathrm{MO}(O M)$ & 34,88 & 35,37 & 37,52 & 36,89 & 36,17 & 17,33 \\
\hline $\mathrm{PB}(C P)$ & 48,02 & 50,66 & 55,64 & 56,33 & 52,66 & 19,80 \\
\hline $\mathrm{EE}$ & 86,19 & 86,93 & 89,47 & 91,55 & 88,54 & 14,90 \\
\hline $\mathrm{CT}(T C)$ & 18,18 & 21,53 & 17,73 & 22,89 & 20,08 & 19,68 \\
\hline FDN $(N D F)$ & 8,64 & 9,52 & 14,52 & $-4,97^{* *}$ & 6,93 & 141,56 \\
\hline $\mathrm{CNF}(N F C)$ & 14,99 & 17,86 & 17,19 & 14,96 & 16,25 & 12,51 \\
\hline
\end{tabular}


Tabela 6 - pH ruminal de bovinos alimentados com dietas à base de silagens de milho e sorgo, com e sem inoculante microbiano Table 6 - Ruminal $\mathrm{pH}$ on steers fed diets containing corn or sorghum silages with and without microbial inoculant

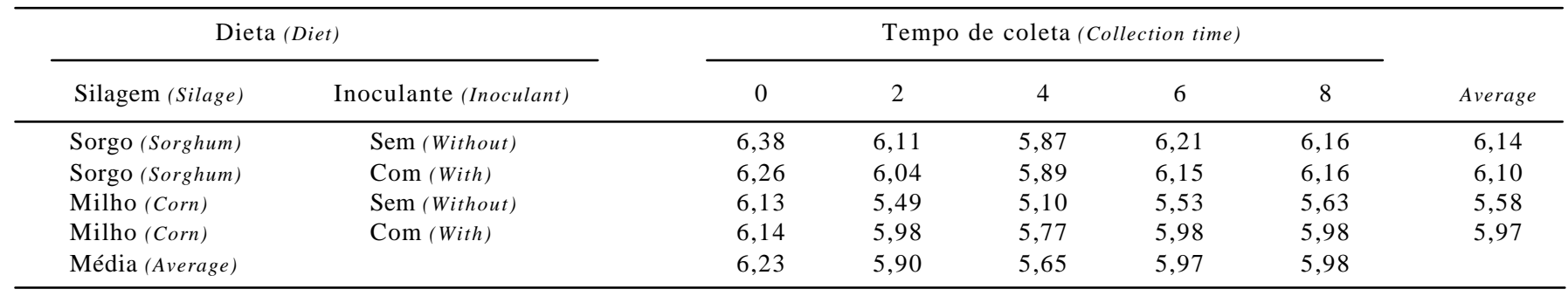

dos tempos de coleta, cujas equações ajustadas encontram-se na Figura 1. Estimaram-se concentrações máximas de amônia $\left(\mathrm{N}-\mathrm{NH}_{3}\right)$ de 9,$47 ; 8,84 ; 10,82$ e $9,04 \mathrm{mg} / 100 \mathrm{~mL}$, respectivamente, às 2,$52 ; 2,77 ; 2,69$ e 2,94 horas após a alimentação com as dietas contendo silagens de sorgo sem e com inoculante e com silagens de milho sem e com inoculante microbiano.

As concentrações de amônia ruminal ( $\left.\mathrm{N}-\mathrm{NH}_{3}\right)$ observadas neste estudo foram superiores à de 3 a $5 \mathrm{mg} / 100 \mathrm{~mL}$, considerada por Harrisson \& Mcallan (1980) limitante à ação de bactérias celulolíticas. Conforme os valores de $\mathrm{pH}$ ruminal e a concentração de amônia ruminal $\left(\mathrm{N}-\mathrm{NH}_{3}\right)$ obtidos ao longo do tempo, pode-se inferir que os substratos presentes nas dietas e as condições ruminais favoreceram a fermentação ruminal.

As taxas de passagem médias, estimadas pelo modelo de Czerkawski (1996), nos animais consumindo dietas contendo silagens de sorgo sem e com inoculante microbiano e silagens de milho sem e com inoculante microbiano foram de 5,$12 ; 4,44 ; 5,05$ e 4,29\%/hora, respectivamente, e não diferiram, registrando-se valor médio de 4,72\%/hora. Estes valores foram próximos dos obtidos por Cone et al. (1999), de 4,0 a 4,8\%/hora, em silagens de gramíneas, e de 4,68\%/ hora, estimado porLondono et al. (1997), em animais recebendo silagens de milho como volumoso. Os valores de taxa de passagem estimados pela equação sugerida pelo NRC (2001) foram de 5,41; 5,37; 4,98 e 5,21\%/hora nos animais consumindo dietas contendo silagens de sorgo sem e com inoculante microbiano e de milho sem e com inoculante microbiano, respectivamente, com valor médio de 5,24\%/ hora, superando em apenas $11 \%$ o estimado pelo modelo de Czerkawski (1986), o que indica a possibilidade de estimação desse componente sem uso de óxido de cromo, reduzindo-se os gastos com esse produto. Todavia, são necessários mais estudos para inferências mais seguras sobre o assunto.

As produções médias estimadas de proteína microbiana foram de 490,79; 495,88; 549,38; e 520,49 g/dia nos animais alimentados com as dietas contendo as

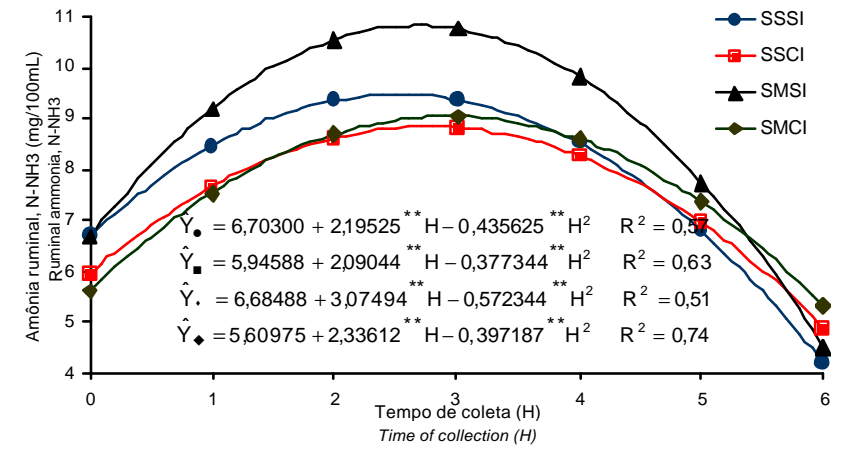

** Significativo a $1 \%$ de probabilidade pelo teste $t$.

** Significant at $1 \%$ of probability by $t$ test.

Figura 1 - Estimativa da concentração de amônia ruminal $\left(\mathrm{N}-\mathrm{NH}_{3}\right)$, em função do tempo de coletas $(H)$, nos animais alimentados com as quatro dietas experimentais.

Figure 1 - Estimated ruminal ammonia concentration $\left(\mathrm{NH}_{3}-\mathrm{N}\right)$ on steers fed diets containing corn or sorghum silages with and without microbial inoculant.

silagens de sorgo sem e com inoculante microbiano e com as silagens de milho sem e com inoculante microbiano, respectivamente, apresentando valor médio de 514,1 g/dia. Segundo o NRC (2001), a carência de dados relacionando a produção microbiana estimada ao desempenho animal é o fator mais limitante para a validação de sua estimativa matemática. Ficou evidente que, numericamente, a produção de proteína microbiana foi maior quando a dieta à base de silagem de milho foi empregada. No entanto, como os resultados observados foram obtidos pela estimativa indireta, são necessárias pesquisas elucidativas para compreensão dos eventos relacionados à síntese e ao aproveitamento desta fonte de nutrientes.

\section{Conclusões}

O consumo e as digestibilidades totais dos nutrientes, o pH e a concentração de amônia ruminal, bem como a taxa de passagem da digesta, não foram influenciados pelas 
dietas experimentais, indicando que as dietas avaliadas foram nutricionalmente equivalentes, não se evidenciando mérito atribuído a silagens confeccionadas com uso do inoculante microbiano.

\section{Literatura Citada}

ALLEN, M.S. Physical constraints on voluntary intake of forages by ruminants. Journal of Animal Science, v.74, n.12, p.3063-3075, 1996.

ARCURI, P.B. Recentes avanços em microbiologia ruminal e intestinal. In: SIMPÓSIO INTERNACIONAL DE BOVINOCULTURA DE LEITE: Novos conceitos em nutrição, 2001, Lavras. Anais... Lavras: Universidade Federal de Lavras, 2001. p.1-24.

BOLSEN, K.K.; LIN, C.; BRENT, B.E. et al. Effect of silage additives on the microbial succession and fermentation process of alfalfa and corn silages. Journal of Dairy Science, v.75, n.11, p.3066-3083, 1992.

CALDAS NETO, S.F.; ZEOULA, L.M.; BRANCO, A.F. et al. Mandioca e resíduos das farinheiras na alimentação de ruminantes: digestibilidade total e parcial. In: REUNIÃO ANUAL DA SOCIEDADE BRASILEIRA DE ZOOTECNIA, 36., 1999, Porto Alegre. Anais... Porto Alegre: Sociedade Brasileira de Zootecnia, 1999 (CD-ROM)

CAVALCANTE, A.C.R.; PEREIRA, O.G.; VALADARES FILHO, S.C. et al. Dietas contendo silagem de milho (Zea maiz) e feno de tifton 85 (Cynodon spp.) em diferentes proporções para bovinos. Revista Brasileira de Zootecnia, v.33, n.6, p.23942402, 2004

CLEALE, R.M.; FIRKINS, J.L.; van der BEEK, F. et al. Effect of inoculation of whole plant corn forage with Pediococcus acidilactici and Lactobacillus xylosus on preservation of silage and heifer growth. Journal of Dairy Science, v.73, n.3, p.711-718, 1990.

CONE, J.W.; Van GELDER, A.H.; SOLIMAN, I.A. et al. Different techniques to study rumen fermentation characteristics of maturing grass and grass silage. Journal of Dairy Science, v.82, n.5, p.957-966, 1999.

CZERLAWSKI, J.W. An introduction to rumen studies. Oxford: Pergamon International Library, 1986. p.31-44.

DEWHURST, R.J.; DAVIES, D.R., MERRY, R.J. Microbial protein supply from the rumen. Animal Feed Science and Technology. v. 85 , p.1-21, 2000 .

DIAS, H.L.C.; VALADARES FILHO, S.C.; COELHO DA SILVA, J.F. et al. Consumo e digestões totais e parciais em novilhos $F_{1}$ Limousin $x$ Nelore alimentados com dietas contendo cinco níveis de concentrado. Revista Brasileira de Zootecnia, v. 29, n.2, p.545-554, 2000.

FROETSCHEL, M.A; NICHOLS, S.W.; ELY, L.O. et al. [1977] Effect of silage inoculant on the fermentation and digestibility of tropical corn and sorghum silages. Disponível em: <http://www.ads.uga.edu/annrpt/1995/ d203froe.htm> Acesso em: 16/06/98

HARRISON, D.G.; McALLAN, A.B. Factors affecting microbial growth yields in the reticulo-rumen. In: RUCKEBUSCH, Y.; THIVEND, P. (Eds.) Digestive physioloy and metabolism ruminants. Lancaster: MTP Press Ltda., 1980. p.205-226.

HOOVER, W.H. Chemical factors involved on ruminal fiber digestion. Journal of Dairy Science, v.69, n.10, p.227-235, 1986.

HUHTANEN, P. The effects of concentrate energy source and protein content on milk production in cows given grass silage ad libitum. Grass Forage Science, v.48, p.347-355, 1993.

HVELPLUND, T. Volatile fatty acids and protein production in the rumen. In: JOUANY, J.P. (Ed.) Rumen microbial metabolism and ruminant digestion. Paris: INRA, 1991. p.165-178.

KUNG JR., L. Silage fermentation and additives. In: SCIENCE AND TEHCNOLOGY IN THE FEED INDUSTRY, 17., 2001, Nottingham. Proceedings... Nottingham: Nottingham University Press, 2001. p.145-159.

KUNG JR., L. Use of additives in silage fermentation. In: Directfed microbial, enzyme \& forage additive compendium Minnetonka: Miller Publishing CO, 1996. p.37-42.

KUNG JR., L., MUCK, R.E. Animal response to silage additives. In: SILAGE: FIELD TO FEEDBUNK, 1997, Pennsylvania. Proceedings... New York: Natural Resource, Agriculture, and Engineering Service, 1997. p.200-210.

LAVEZZO, O.E.N.M.; LAVEZZO, W.; SIQUEIRA, E.R. Estádio de desenvolvimento do milho.2. Efeito sobre o consumo e a digestibilidade da silagem em ovinos. Revista Brasileira de Zootecnia, v.26, n.4, p.683-690, 1997.

LADEIRA, M.M.; VALADARES FILHO, S.C.; COELHO DA SILVA, J.F. et al. Consumo e digestibilidades aparentes totais e parciais de dietas contendo diferentes níveis de concentrado, em novilhos Nelore. Re vista Brasileira de Zootecnia, v.28, n.2, p.395-403, 1999.

LONDOÑO, A.A.S.; VALADARES FILHO, S.C.; SILVA, J.F.C. et al. Somatotropina bovina para vacas em lactação. 2. Consumo, digestibilidade aparente e concentrações ruminais de amônia, pH e taxa de passagem. Revista Brasileira de Zootecnia, v.26, n.6, p.1234-1242, 1997.

LUTHER, R.M. Effect of microbial inoculation of whole plant corn-silage on chemical characteristcs preservation and utilization by steers. Journal of Animal Science, v.63, n.5, p.1329-1336, 1986.

MEESKE, R.; BASSON, H.M. The effect of a lactic acid bacterial inoculant on maize silage. Animal Feed Science and Technology, v.70, n.3, p.239-247, 1998.

MERCHEN, N.R. Digestion, absorcion y excrecion en los rumiantes. In: CHURCH, D.C. (Ed.) El rumiante: fisiologia digestiva y nutrición. Zaragosa: Acríbia, 1988. p.191-223.

MERTENS, D. Using fiber and carbohydrate analyses to formulate dairy rations. In: INFORMATIONAL CONFERENCE WITH DAIRY AND FORAGE INDUSTRIES, 1996, Madison. Proceedings... Wisconsin: U. S. Dairy Forage Research Center, 1996. p.81-92.

MUCK, R.E. The role of silage additives in making high quality silage. New York: Natural Resource, Agriculture, and Engineering Service, 1993. n.67, p.106-116.

NATIONAL RESEARCH COUNCIL - NRC. Nutrients requirements of beef cattle. 7.ed. Washington, D.C.: National Academy Press, 1996. 242p.

NATIONAL RESEARCH COUNCIL - NRC. Nutrients requirements of dairy cattle. 7.ed. Washington, D.C.: National Academy Press, 2001. 381p.

NOLLER, C.H.; MOE, P.W. Determination of NRC energy and protein requeriments for ruminants. In: SIMPÓSIO INTERNACIONAL SOBRE EXIGÊNCIAS NUTRICIONAIS DE RUMINANTES, 1995, Viçosa, MG. Proceedings... Viçosa, MG: Universidade Federal de Viçosa, 1995. p.53-101.

ØRSKOV, E.R. Protein and energy evaluation in ruminant with emphasis on total resource management. In: SIMPÓSIO INTERNACIONAL DE DIGESTIBILIDADE EM RUMINANTES, 1997, Lavras. Anais... Lavras: Universidade Federal de Lavras, 1997. p.115-126.

PEREIRA, O.G.; RIBEIRO, K.G. Suplementação de bovinos com forragens conservadas. In: SIMPÓSIO DE PRODUÇÃO DE GADO DE CORTE, 2., 2001, Viçosa, MG. Anais... Viçosa, MG: Universidade Federal de Viçosa, 2001. p.261-289.

RIBEIRO, K.G.; GARCIA, R.; PEREIRA, O.G. et al. Consumo e digestibilidade aparentes total e parcial, de nutrientes, em bovinos recebendo rações contendo feno de capim-Tifton 85 , em diferentes idades de rebrota. Revista Brasileira de Zootecnia, v.30, n.2, p.573-580, 2001. 
RODRIGUES, M.T. Uso de fibras em rações de ruminantes. In: CONGRESSO NACIONAL DOS ESTUDANTES DE ZOOTECNIA, 1998, Viçosa, MG. Anais... Viçosa, MG: Associação Mineira dos Estudantes de Zootecnia, 1998. p.139-171.

RUSSEL, J.B.; O'CONNOR, J.D.; FOX, D.G. A net carbohydrate and protein system for evaluating cattle diets. I. Ruminal fermentation. Journal of Animal Science, v.70, n.11, p.3551-3561, 1992.

SANDERSON, M.A. Aerobic stability in vitro fiber digestibility of microbially inoculated corn and sorghum silages. Journal of Animal Science, v.71, n.2, p.505-514, 1993.

SILVA, D.J. Análise de alimentos (Métodos químicos e biológicos). Viçosa, MG: Universidade Federal de Viçosa, 1998. $165 \mathrm{p}$.

SNIFFEN, C.J.; BEVERLY, R.W.; MOONEY, C.S. et al. Nutrient requirements versus supply in the dairy cow: strategies to account for variability. Journal Dairy Science, v.76, n.10, p.31603178, 1993.

SNIFFEN, C.J.; O'CONNOR, J.D.; Van SOEST, P.J. et al. A net carbohydrate and protein system for evaluation cattle diets. II. Carbohydrate and protein availability. Journal of Animal Science, v.70, n.11, p.3562-3577, 1992.
UNIVERSIDADE FEDERAL DE VIÇOSA - UFV.SAEG - Sistema de análises estatísticas e genéticas. Versão 8.0. Viçosa, MG, 2000. 150p. (Manual do usuário).

Van SOEST, P.J.; MERTENS, D.R.; EDINUM, B. Preharvest factors influencing quality of conserved forage. Journal of Animal Science, v.47, n.3, p.712-720, 1978.

WEIBERG, Z.G.; MUCK, R.E. New trends and opportunities in the development and use of inoculants for silage. FEMS Microbiology Reviews, v,19, p,53-68, 1996.

WEIBERBERG, Z.G.; CHEN, Y.; GAMBURG, M. The passage of lactic acid bacteria from silage into rumen fluid, in vitro studies. Journal of Dairy Science, v.87, n.10, p.3386-3397, 2004. 